\title{
Vancomycin Hydrochloride
}

National Cancer Institute

\section{Source}

National Cancer Institute. Vancomycin Hydrochloride. NCI Thesaurus. Code C65207.

The hydrochloride salt of vancomycin, a branched tricyclic glycosylated peptide with bactericidal activity against most organisms and bacteriostatic effect on enterococci. At a site different from that of penicillins and cephalosporins, vancomycin binds tightly to the D-alanyl-D-alanine portion of cell wall precursors, thereby interfering with bacterial cell wall synthesis. This leads to activation of bacterial autolysins that destroy the cell wall by lysis. Vancomycin may also alter the permeability of bacterial cytoplasmic membranes and may selectively inhibit RNA synthesis. 